\title{
PM10, and children's respiratory symptoms and lung function in the PATY study
}

\author{
Gerard Hoek, Sam Pattenden, Saskia Willers, Temenuga Antova, \\ Eleonora Fabianova, Charlotte Braun-Fahrländer, Francesco Forastiere, \\ Ulrike Gehring, Heike Luttmann-Gibson, Leticia Grize, Joachim Heinrich, \\ Danny Houthuijs, Nicole Janssen, Boris Katsnelson, Anna Kosheleva, \\ Hanns Moshammer, Manfred Neuberger, Larisa Privalova, Peter Rudnai, \\ Frank Speizer, Hana Slachtova, Hana Tomaskova, \\ Renata Zlotkowska and Tony Fletcher
}

ABSTRACT: Studies of the impact of long-term exposure to outdoor air pollution on the prevalence of respiratory symptoms and lung function in children have yielded mixed results, partly related to differences in study design, exposure assessment, confounder selection and data analysis.

We assembled respiratory health and exposure data for $>45,000$ children from comparable crosssectional studies in 12 countries. 11 respiratory symptoms were selected, for which comparable questions were asked. Spirometry was performed in about half of the children. Exposure to air pollution was mainly characterised by annual average concentrations of particulate matter with a $50 \%$ cut-off aerodynamic diameter of $10 \mu \mathrm{m}\left(\mathrm{PM}_{10}\right)$ measured at fixed sites within the study areas.

Positive associations were found between the average $\mathrm{PM}_{10}$ concentration and the prevalence of phlegm (OR per $10 \mu \mathrm{g} \cdot \mathrm{m}^{-3} 1.15,95 \% \mathrm{Cl} 1.02-1.30$ ), hay fever (OR $1.20,95 \% \mathrm{Cl} 0.99-1.46$ ), bronchitis (OR 1.08, 95\% Cl 0.98-1.19), morning cough (OR 1.15, 95\% Cl 1.02-1.29) and nocturnal cough (OR 1.13, 95\% $\mathrm{Cl}$ 0.98-1.29). There were no associations with diagnosed asthma or asthma symptoms. PM10 was not associated with lung function across all studies combined.

Our study adds to the evidence that long-term exposure to outdoor air pollution, characterised by the concentration of PM10, is associated with increased respiratory symptoms.

KEYWORDS: Child, lung function, nitrogen dioxide, particulate matter, respiratory symptoms

hort-term increases in outdoor air pollution have been associated with respiratory symptoms and temporary lung function decreases $[1,2]$. The impact of long-term exposure to outdoor air pollution on prevalence of respiratory symptoms and lung function in children has been investigated in studies around the world [3-15]. Results concerning symptoms have been mixed, with more evidence for significant effects of outdoor air pollution on bronchitis or symptoms such as cough and phlegm than on asthma or asthmatic symptoms such as wheeze. Results from crosssectional studies of lung function in children were also mixed [14]. Several prospective studies documented significant effects of outdoor air pollution on lung function development, e.g. the Californian Children's Health Study [14, 15]. Some of the inconsistencies in reported associations between air pollution and lung function may be due to differences in study design [14]. Studies differ in their study area (air pollution exposure contrasts between communities versus within a community), measured pollutants (particulate matter, sulphur dioxide, nitrogen dioxide and ozone), wording of symptom questions, study population (either population based or high risk), inclusion of potential confounders and statistical methods. Particulate matter air pollution has been represented with various indices, including total suspended particulate matter (TSP), particulate matter with a $50 \%$ cut-off aerodynamic diameter of $10 \mu \mathrm{m}$ (PM10) or $2.5 \mu \mathrm{m}$ (PM2.5). Some studies have reported higher air pollution effect estimates on lung function for females $[7,12]$, but the evidence is currently not convincing [14]. In the Children's Health study, air pollution effects on symptoms were stronger in males [8], whereas the effects on lung function were stronger in females [7]. Interpretation of subgroup analysis in single studies is difficult as the power to detect significant interactions is limited.
AFFILIATIONS

Author affiliations are listed in the Acknowledgements section.

CORRESPONDENCE

G. Hoek

Institute for Risk Assessment Sciences

University of Utrecht PO Box 80178 3508 TD Utrecht The Netherlands E-mail: g.hoek@uu.nl

\section{Received:}

Jan 072011

Accepted after revision: Dec 092011

First published online: April 202012 
To overcome some of these shortcomings, the Pollution and the Young (PATY) project assembled health and exposure data for 58,561 children from comparable cross-sectional studies in 12 countries on children's respiratory health. Pooling original data allowed harmonisation of data analysis and definition of confounders, pursuit of research questions not addressed originally, and inclusion of unpublished studies. We made further use of the large dataset to assess effect modification with more precision than single studies. We already published on associations between outdoor $\mathrm{NO}_{2}$ and respiratory symptoms in a subset of the five PATY studies with $\mathrm{NO}_{2}$ exposure data [16]. In the current article, we examine the association between ambient fine particulate matter (PM10) in all PATY studies and prevalence of respiratory symptoms and lung function.

\section{METHODS}

\section{Study design}

Cross-sectional studies of children were sought that assessed respiratory symptoms and individual risk factors by questionnaire, included cough and wheeze as outcomes, and allowed calculation of annual mean particulate matter measures by study area. We included all cross-sectional studies that were available at the onset of the study. From the USA and the Netherlands, we included only the most recent and largest study, excluding the Six City and Six School studies [14]. Table 1 describes the studies contributing to this paper. More details on the individual studies can be found elsewhere $[4,10$, 11, 13, 16, 18-20]. The studies from Russia, Central and Eastern Europe and Italy have not previously published results of air pollution analysis in the English language. The study areas were of substantially different magnitude. The Austrian and Czech study was performed in one city, and the North American study included a very large area in the USA and Canada. We therefore anticipated some heterogeneity in effects, which was taken into account in the analysis. All studies had obtained permission from the relevant medical ethical committees.

\section{Health data}

Original questionnaires were translated into English and critically examined for comparability of wording. 11 comparable symptom outcomes were identified: wheeze in the past 12 months, asthma ever, bronchitis in the past 12 months, phlegm, nocturnal dry cough in the past 12 months, morning cough in the past 12 months, sensitivity to inhaled allergens, hay fever ever, itchy rash ever, woken by wheeze in the past 12 months and allergy to pets. The exact wording of the symptom questions in all studies has been reported previously [21].

Several of the studies also performed spirometry (table 1). All studies used equipment that fulfilled either the 1987 criteria of the American Thoracic Society (ATS) or the 1993 European Respiratory Society (ERS) criteria. Spirometry was performed using the 1987 protocol of the ATS (North American, German and Austrian studies) or the 1993 ERS (CESAR study and the Netherlands). Further details have been published previously [17]. The main lung function measures of interest were forced vital capacity (FVC), forced expiratory volume in $1 \mathrm{~s}$ (FEV1), peak expiratory flow and the forced expiratory flow at $25-75 \%$ of the FVC (FEF25-75\%).

\section{Exposure assessment methods}

The main exposure of interest was the annual mean concentration of PM10 in the corresponding study area. Data on the gaseous pollutants $\mathrm{NO}_{2}$ and $\mathrm{SO}_{2}$ were also obtained. In all studies, air pollution concentrations were measured at fixed monitoring sites in the study area. To assess the comparability of monitoring sites and monitoring methods, a standard questionnaire was discussed with the investigators of the studies (online supplementary material pages 2 and 3 and tables S1 and S2). Briefly, PM10 was directly measured specifically for the study with Harvard impactors in Switzerland, the CESAR study, and for Russia and North America. In the Netherlands, Austria and Germany, particulate matter measurements were converted to gravimetric PM10 using co-located measurements with a standard particulate matter sampler in the study area. In the Italian study, multiple particulate matter monitoring methods were used and there was insufficient colocation with standard PM10 equipment to allow calculation of a consistent PM10 concentration. The evaluation further resulted in a few modifications of the original exposure estimates and exclusions of a few areas because of unrepresentative monitoring sites (online supplementary material pages 2 and 3 ).

\section{Data analysis}

A priori, we assessed that air pollution exposure contrasts between countries could not be exploited, as differences in language and (unmeasured) major risk factors were likely to be more dominant determinants for the health outcomes (especially with regards to symptoms). Hence, a two-stage analysis approach was used. In stage one, study-specific PM10 effects were estimated using logistic regression for symptoms and linear regression for lung function. This approach also has the advantage that systematic differences in PM10 sampler performance between studies do not affect the results. An area-level random intercept was included to account for clustering within the study areas. The CESAR study was conducted in five countries and, although common methods were used, the study was analysed per country. In stage two, effect estimates and standard errors were entered into a metaanalysis, obtaining a mean estimate, and a measure and Cochran Chi-squared test of heterogeneity using the STATA (StataCorp, College Station, TX, USA) metan command. Estimation of this mean and its confidence interval takes into account both between-study variation in effects and uncertainty of study-specific estimates [22]. In the first stage, we controlled for age, sex, maternal education, paternal education, household-crowding, current parental smoking, mother smoking during pregnancy, gas cooking, unvented gas/oil/kerosene heater, mould, nationality, birth order and "ever had a pet" [16]. Lung function analyses were additionally adjusted for age, height, weight, technician, instrument, season of testing and reported infection on the day of the test. The natural logarithm of lung function variables was used as the dependent variable to allow for non-normal distribution and nonlinear associations with anthropometric variables [17]. The natural logarithm of age, weight and height (sex-specific using an interaction term) were included as predictors following the North American study [13]. We further calculated predicted values for FVC, FEV1 and FEF25-75\% using recently published prediction equations and used the \% predicted lung function as the dependent variable in an additional analysis [23]. 


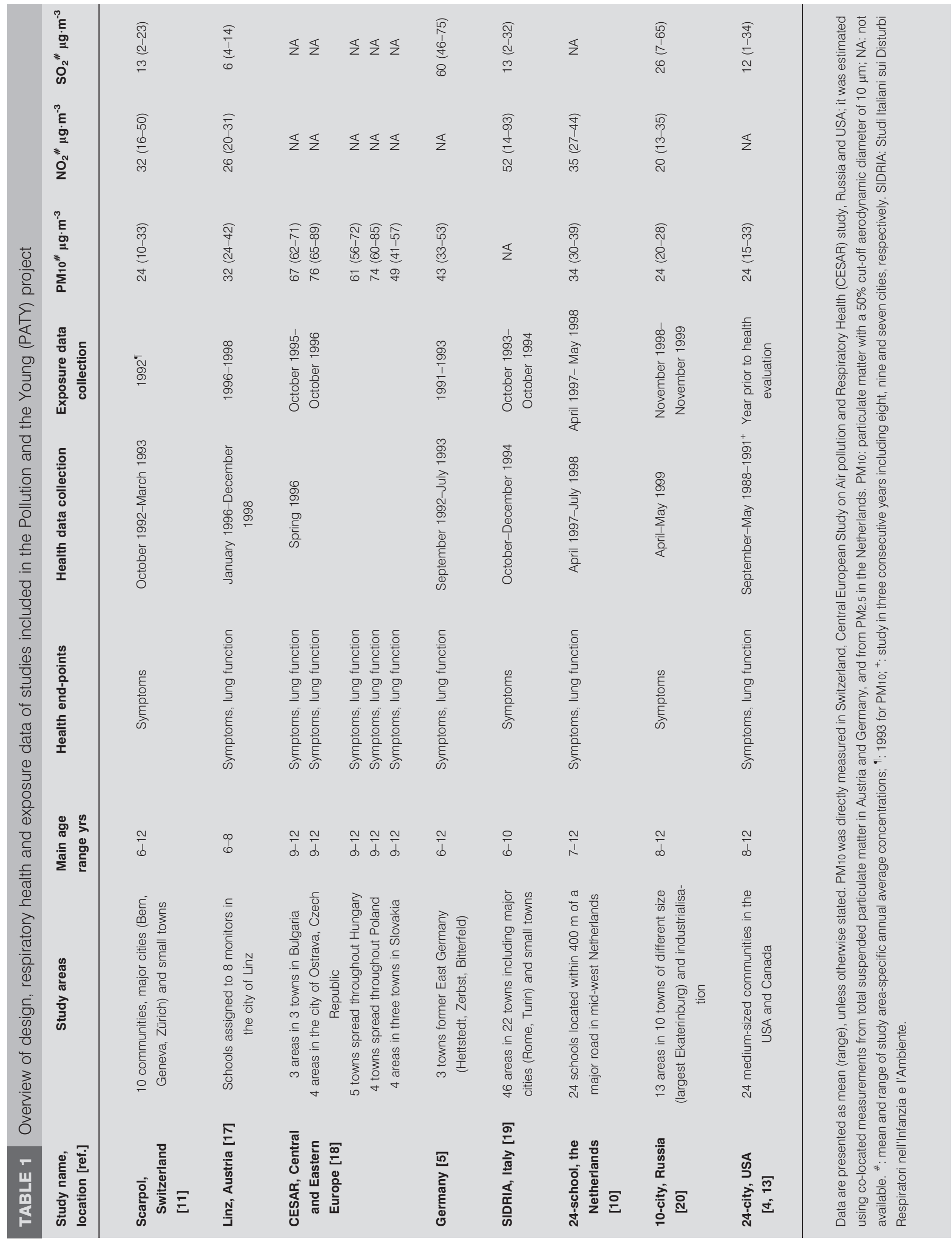


Meta-regressions assessed associations between study-specific estimates and study characteristics. These a priori-defined potential sources of heterogeneity between estimates were study period, design type (between-city, within-city or mixed design), location of monitoring station, proportion of younger children (6-8 yrs), questionnaire-date variability across study areas, high response rate $(>80 \%)$ and response-rate variability across study areas.

Subgroup analyses were conducted in the first stage to assess individual subject characteristics as a source of heterogeneity. We stratified by sex, age and reporting of wheeze, and sensitisation (the latter for lung function only).

All analyses were performed using STATA version 8 (StatCorp).

\section{RESULTS}

\section{Associations between air pollution and respiratory symptoms}

Data were available from 11 studies on PM10 and symptoms (table 1). The highest PM10 concentrations were measured in the Central and Eastern European areas. The range in concentration within a study was largest in the North American and Swiss studies (ratio of maximum to minimum larger than two) (fig. 1).

Complete information on health and covariates was available for 45,788 children. About one-third of the children were from the North American study (table 2). Several-fold differences in symptom prevalence were found between countries, probably partly related to cultural differences and subtle differences in wording of the question.

After adjustment for confounders, PM10 was significantly associated with phlegm and morning cough (table 3 and fig. 2). Associations between PM10 and a doctor diagnosis of bronchitis, nocturnal cough and hay fever were borderline significant. Significant heterogeneity between study-specific estimates was found for most outcomes. The most consistent pattern was found for phlegm and hay fever, for which most study-specific effect estimates were either positive or slightly negative (fig. 2). For bronchitis and the two cough variables, both positive and negative effect estimates were found. A diagnosis of asthma and the symptoms wheeze and being woken by wheeze were not associated with PM10. Meta-regression could not identify significant factors at the study level explaining the observed

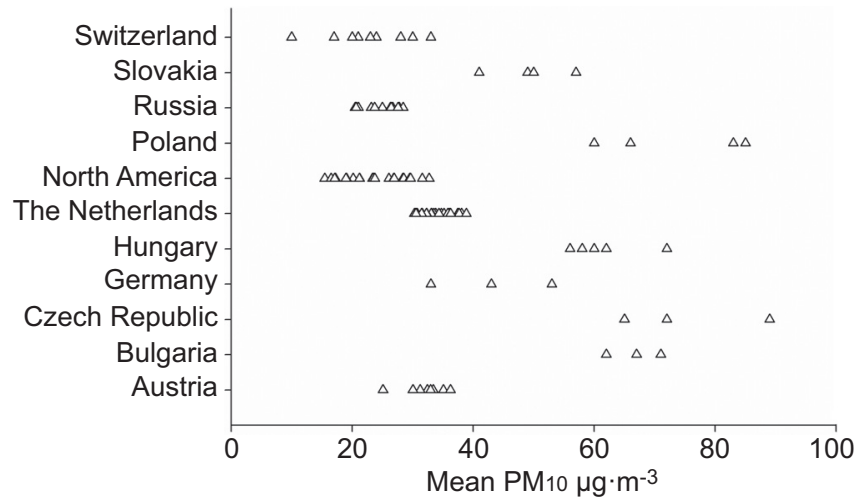

FIGURE 1. Annual average concentrations of particulate matter with a $50 \%$ cut-off aerodynamic diameter of $10 \mu \mathrm{m}$ (PM10) per study area, within each country.

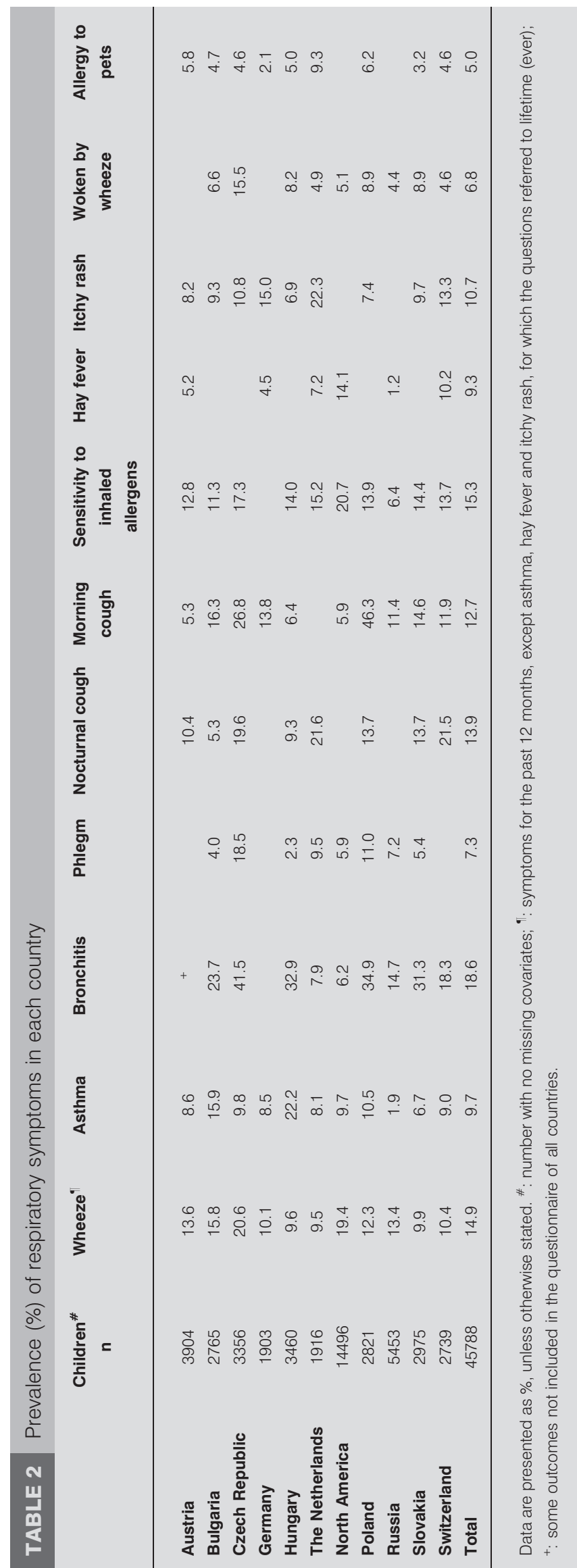




\begin{tabular}{|c|c|c|}
\hline \multirow[t]{3}{*}{ TABLE 3} & $\begin{array}{l}\text { tion between pre } \\
\text { ns and long-term } \\
\text { ulate matter with } \\
\text { amic diameter o }\end{array}$ & $\begin{array}{l}\text { e of respiratory } \\
\text { ge concentration } \\
\text { \% cut-off } \\
\text { n (PM10) }\end{array}$ \\
\hline & \multicolumn{2}{|c|}{ Mean OR $(95 \% \mathrm{Cl})$} \\
\hline & Age-sex adjusted & Fully adjusted $^{\#}$ \\
\hline Wheeze & $1.03(0.95-1.11)^{\circ}$ & $1.01(0.95-1.09)$ \\
\hline Asthma & $0.99(0.92-1.08)$ & $1.03(0.97-1.10)$ \\
\hline Bronchitis & $1.06(0.94-1.21)^{\circ}$ & $1.08(0.98-1.19)^{\circ}$ \\
\hline Phlegm & $1.16(1.02-1.31)^{\circ}$ & $1.15(1.02-1.30)^{\circ}$ \\
\hline Nocturnal cough & $1.15(1.00-1.32)^{\circ}$ & $1.13(0.98-1.29)^{\circ}$ \\
\hline Morning cough & $1.16(1.02-1.32)^{\bullet}$ & $1.15(1.02-1.29)^{\circ}$ \\
\hline $\begin{array}{l}\text { Sensitivity to inhaled } \\
\text { allergens }\end{array}$ & $1.01(0.90-1.13)^{\bullet}$ & $1.02(0.93-1.11)$ \\
\hline Hay fever & $1.18(0.96-1.44)$ & $1.20(0.99-1.46)$ \\
\hline Itchy rash & $1.04(0.98-1.11)$ & $1.07(0.96-1.19)^{\circ}$ \\
\hline Woken by wheeze & $1.04(0.94-1.14)^{\circ}$ & $1.01(0.92-1.12)$ \\
\hline Allergy to pets & $1.18(0.95-1.46)^{\bullet}$ & $1.18(0.96-1.45)^{\circ}$ \\
\hline
\end{tabular}

Odds ratios (ORs) are combined effect estimates from single pollutant models calculated from country-specific estimates using random effects model. Mean ORs and $95 \%$ confidence intervals are given per $10 \mu \mathrm{g} \cdot \mathrm{m}^{-3}$ increase in PM10. \#: adjusted for age, sex, maternal education, paternal education, householdcrowding, current parental smoking, mother smoking during pregnancy, gascooking, unvented gas/oil/kerosene heater, mould, nationality, birth order and "ever had a pet"; ": evidence of between-study heterogeneity $(p<0.10)$.

heterogeneity in effect estimates. Table S3 presents the data for the symptom phlegm.

Two-pollutant models were employed for symptoms showing (borderline) significant associations with PM10 in the singlepollutant model (table 4). Adjustment for $\mathrm{SO}_{2}$ made little difference to the PM10 effect estimates with the exception of bronchitis, which showed a substantial decrease (single versus two pollutant PM10 estimates table 4). Adjustment for $\mathrm{NO}_{2}$ made little difference to the PM10 effect estimates for bronchitis, phlegm, morning cough and hay fever. For the symptoms of nocturnal cough, sensitivity to inhaled allergens, itchy rash and allergy to pets, after inclusion of $\mathrm{NO}_{2}$, the PM10 effect estimates were reduced. Correlations ( $\mathrm{r}$ ) between the annual average concentration of $\mathrm{NO}_{2}$ and PM10 in the studies with $\geqslant 10$ study areas ranged from 0.48 to 0.84 . Correlations between $\mathrm{SO}_{2}$ and PM10 ranged from 0.36 to 0.82 .

PM10 effect estimates did not differ significantly between males and females, or between the younger and older children in the study population (table S4). Associations for hay fever and allergy to pets were stronger in the older children, but the difference with the younger children was not significant. Effect of PM10 on nocturnal cough and allergy to pets were stronger in boys than in girls but the differences did not reach statistical significance.

\section{Associations between air pollution and lung function}

Valid lung function data were available for 22,809 children (table S5). About $60 \%$ of the children with a valid lung function test were from the North American study. While in the North American, German, Austrian and Dutch studies, the percentage of children with a valid lung function test was well over $80 \%$, it ranged from between 26 and $60 \%$ for the four CESAR study countries. This was related to too early termination of the test, resulting in too low FVC values. In all studies except the Austrian study, the mean percentage predicted lung function using the Stanojevic equations was close to 100.

On average, no association was found between the average PM10 concentration of the study area and lung function (fig. 3). In individual studies, both increases (Slovakia) and decreases (North America and Poland) in lung function were found with increasing PM10. Removing the CESAR countries from the analysis did not change the associations substantially (table S6). Analysis of the data using the recent Stanojevic prediction equations also resulted in no significant associations between PM10 and lung function (table S6).

There were no significant differences in PM10 effect estimates between males and females or younger and older children (table 5).

\section{DISCUSSION}

Statistically (borderline) significant positive associations were found between PM10 and the prevalence of phlegm, morning cough, hay fever, bronchitis and nocturnal cough. There were no associations with diagnosed asthma and asthma symptoms. PM10 effect estimates did not differ between males and females. PM10 was not associated with lung function.

The main strength of our study is the large number of children $(45,000)$ taken from studies in 12 countries. This reduces the risk of finding spurious associations due to, for example, unmeasured confounding at the study area level as in single studies. The large study size also allowed for analyses of subgroups with more precision. Compared with a standard meta-analysis of studies, our study offers several advantages related to having the original data of all the studies available instead of only the air pollution effect estimates. First, we selected end-points for a common analysis that were considered sufficiently similar in wording. Secondly, the same data analysis procedures were used, including a common set of confounders. Thirdly, the comparability of exposure data collection could be assessed in detail, which resulted in the removal of some study areas from the epidemiological analysis. Finally, several unpublished studies were included in the analysis.

\section{Comparison with previous studies}

Our findings of significant associations between PM10 and respiratory symptoms and no associations with lung function are in agreement with the Harvard Six City study and two German studies, which were not included in the current analysis [3, 9, 24]. In contrast, other studies not included in the PATY study did find associations between long-term average air pollution exposure and lung function [14]. For the studies included in the PATY study the large North American study found associations with both lung function and bronchitis [13], whereas the Dutch, German and CESAR studies [5, 10, 18] did not find lung function associations.

The effect of air pollution may have been too modest to be reflected in detectable changes of lung function. The (asthma) 

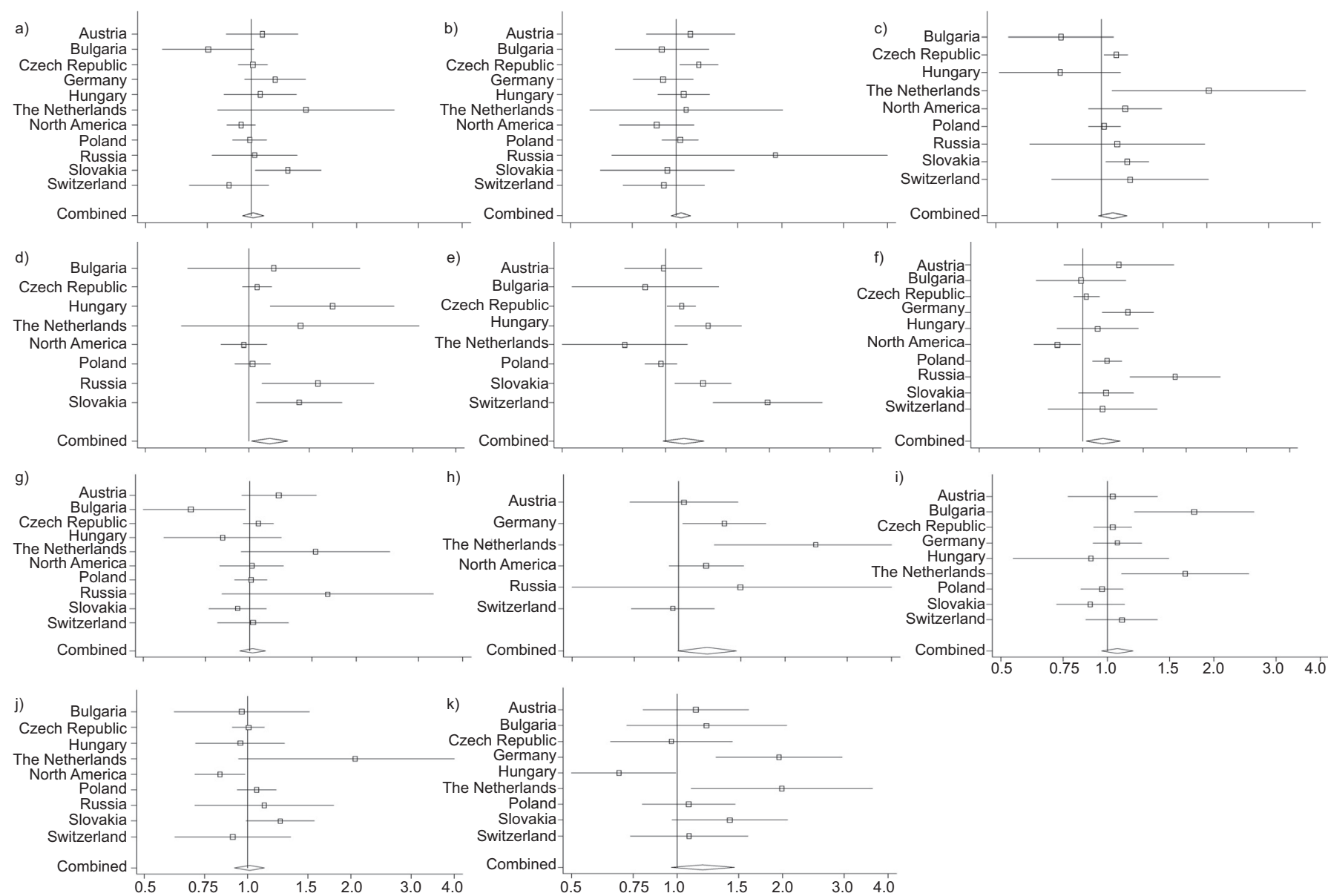

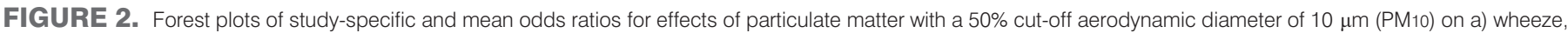

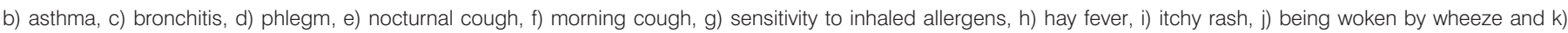

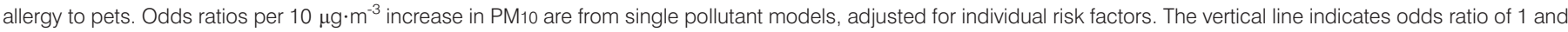

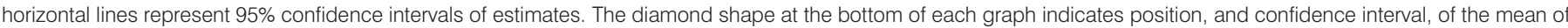
the estimates. Symptoms are for the past 12 months, except asthma, hay fever and itchy rash, which refer to lifetime (ever).

symptoms related to the largest deficits in lung function were also not associated with outdoor air pollution. Alternatively, different biases in the analysis of symptoms and lung function may explain the inconsistencies. First, the typically small effects of air pollution on lung function may have been masked by factors such as variability in coaching and judgement by the technician, instrument, subtle shifts in instrument calibration, short-term weather factors and (past) infections [10]. In the CESAR study, good-quality tests were only obtained in $<50 \%$ of the children, despite a rigorous quality assurance/quality control protocol. Exclusion of the CESAR study countries from the analysis, however, did not change our results. Secondly, reporting bias of symptoms may explain some of the positive associations in studies where parents of the children are aware of high air pollution exposures. This is an unlikely explanation, especially in the North American study where none of the included cities was highly polluted by local sources, and the Dutch study where all schools were located within $400 \mathrm{~m}$ from a major road. The pattern of associations, with bronchitis but not asthma, also makes reporting bias unlikely. Thirdly, lung function data were available for a smaller subset of children, but the precision of estimated effects on lung function was good because of pooling data from a large number of children. Fourthly, pollution levels were moderate. Air pollution may affect lung function at higher pollution levels, such as in many developing countries. Longitudinal studies in highly polluted Mexico City support this [14]. Fifthly, spirometry was performed with now updated guidelines. The updates in performance of testing are probably not sufficiently major to explain the lack of overall associations in our study. We further showed that the use of recent prediction equations for spirometry also resulted in no association between PM10 and lung function. Finally, we only included cross-sectional studies. Several prospective studies have found associations between air pollution and lung function growth, although a series of Austrian studies did not find consistent effects of particulate matter [14].

\section{Heterogeneity of effects}

Despite the efforts to select symptoms with similar wording and harmonise confounder data and data analysis, significant heterogeneity was present in both the symptom and lung function country-specific effect estimates. A priori-defined study-level factors could not explain this heterogeneity, possibly related to the relatively small number of studies. 


\begin{tabular}{|c|c|c|c|}
\hline & \multirow[t]{2}{*}{ Studies $\mathbf{n}$} & \multicolumn{2}{|c|}{ Mean OR $(95 \% \mathrm{Cl})^{\#}$} \\
\hline & & Single-pollutant model & Two-pollutant model \\
\hline \multicolumn{4}{|l|}{ Bronchitis } \\
\hline \multicolumn{4}{|l|}{ Phlegm } \\
\hline In studies with $\mathrm{SO}_{2}$ data & 2 & $1.23(0.81-1.89)^{\bullet}$ & $1.24(0.80-1.94)^{\circ}$ \\
\hline In studies with $\mathrm{NO}_{2}$ data & 2 & $1.55(1.11-2.18)$ & $1.55(1.01-2.38)$ \\
\hline \multicolumn{4}{|l|}{ Nocturnal cough } \\
\hline In studies with $\mathrm{SO}_{2}$ data & 2 & $1.41(0.68-2.93)^{\bullet}$ & $1.43(0.61-3.36)^{\circ}$ \\
\hline \multicolumn{4}{|l|}{ Hay fever } \\
\hline In studies with $\mathrm{SO}_{2}$ data & 5 & $1.13(0.98-1.31)$ & $1.19(1.01-1.40)$ \\
\hline In studies with $\mathrm{NO}_{2}$ data & 4 & $1.22(0.84-1.78)^{\circ}$ & $1.18(0.70-1.97)$ \\
\hline \multicolumn{4}{|l|}{ Itchy rash } \\
\hline In studies with $\mathrm{SO}_{2}$ data & 3 & $1.05(0.93-1.19)$ & $1.13(0.97-1.33)$ \\
\hline In studies with $\mathrm{NO}_{2}$ data & 3 & $1.18(0.94-1.50)$ & $0.91(0.48-1.71)^{\circ}$ \\
\hline \multicolumn{4}{|l|}{ Allergy to pets } \\
\hline In studies with $\mathrm{SO}_{2}$ data & 3 & $1.31(0.90-1.90)^{\circ}$ & $1.16(0.88-1.52)$ \\
\hline In studies with $\mathrm{NO}_{2}$ data & 3 & $1.25(0.92-1.70)$ & $0.87(0.42-1.80)^{\circ}$ \\
\hline
\end{tabular}

Combined effect estimates calculated from country-specific estimates using random effects model. * : adjusted for age, sex, maternal education, paternal education, household crowding, current parental smoking, mother smoking during pregnancy, gas cooking, unvented gas/oil/kerosene heater, mould, nationality, birth order, and "ever had a pet" and expressed per 10- $\mu \mathrm{g} \cdot \mathrm{m}^{-3}$ increase in PM10; ": evidence of between study heterogeneity $(\mathrm{p}<0.10)$.

Differences in study design may have contributed to the observed heterogeneity. Six of the included studies assessed exposure contrasts between communities (Switzerland, Germany, North America, Poland, Hungary and Bulgaria), two studies assessed within-community contrasts (Austria and the Czech Republic), and in the remaining three studies exposure contrasts derived from a mixture of between and within community contrasts. The major common exposure variable PM10 is likely to represent different air pollution mixtures in the different studies, with longrange transported particles contributing only in studies with a between-community component and freshly emitted (ultrafine) particles contributing more to the contrast in the within-city studies. However, particles emitted by motorised traffic have contributed to the exposure contrast in all studies. Within the PATY study, there was no consistent pattern of stronger effects for those studies with a strong traffic-exposure component.

We did not find any difference in effect estimates between males and females, either for symptoms or for lung function. In previous single studies, stronger effects were reported for females in some studies [7, 12] and males in other studies [8].

\section{Limitations}

The small number of study areas is a limitation in some of our studies, although in Switzerland, Russia, the Netherlands and North America, the number of areas was fairly large $(\geqslant 10)$.
The annual average concentration of PM10 was the main exposure variable within the PATY study. We also evaluated $\mathrm{NO}_{2}$ and $\mathrm{SO}_{2}$ as pollutants representing the urban air pollution mixture, but the number of studies with data on multiple pollutants was limited. Hence, the ability to assess effects of PM10 independent of the gaseous pollutants was limited. Twopollutant models are difficult to interpret, especially when the same source affects both pollutants, as is the case for PM10 and $\mathrm{NO}_{2}$, for which motorised traffic is an important source. We cannot exclude that other pollutants such as the soot or elemental carbon content of particulate matter or the ultrafine particle concentration were associated more strongly with the health outcomes.

Several studies have assessed indicators of motorised-traffic emissions at a fine spatial scale $(<100-300 \mathrm{~m})[6,10,12,24]$. Our central monitoring data do not reflect these fine-scale air pollution variations. Because we did not have access to individual addresses, we were unable to generate individual exposure estimates at the residential address. Hence, our study does not provide information on the role of primary traffic emissions. Although this is a limitation, studies comparing the average concentration across communities remain valuable, as they allow estimation of the potential health effects of more aged pollution mixtures. Furthermore, a large fraction of the population does not live directly on major roads. Personal monitoring studies have shown that the population average 
a)

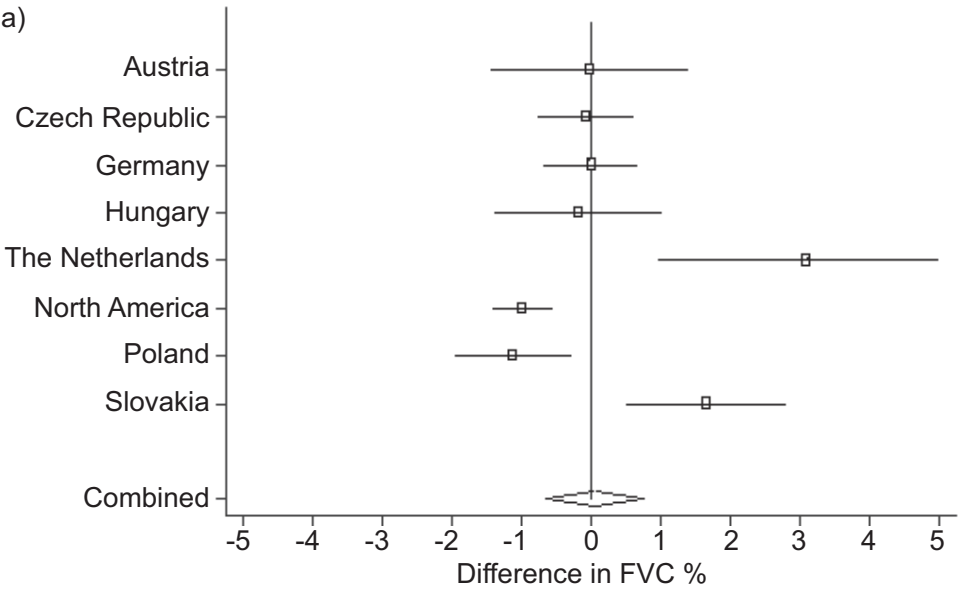

c)

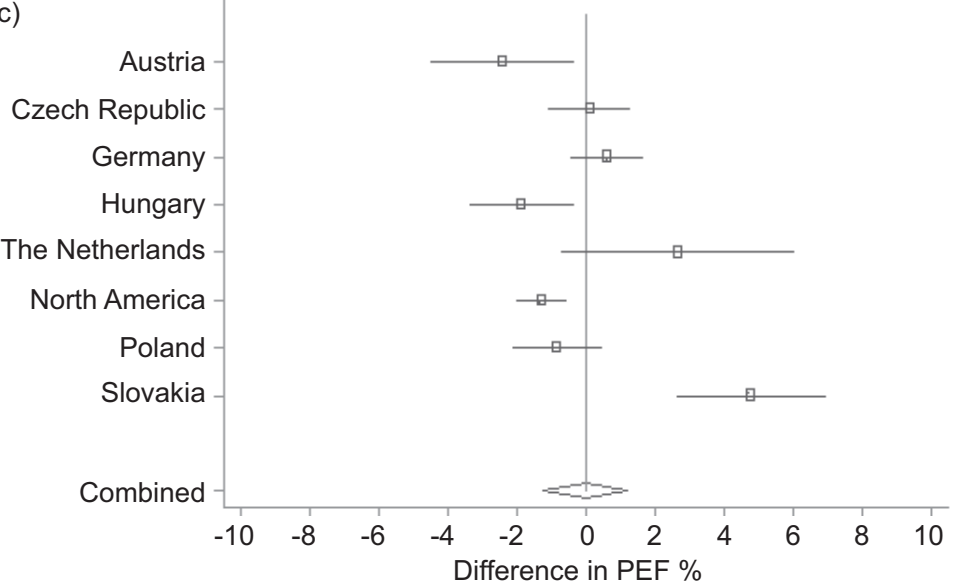

b)

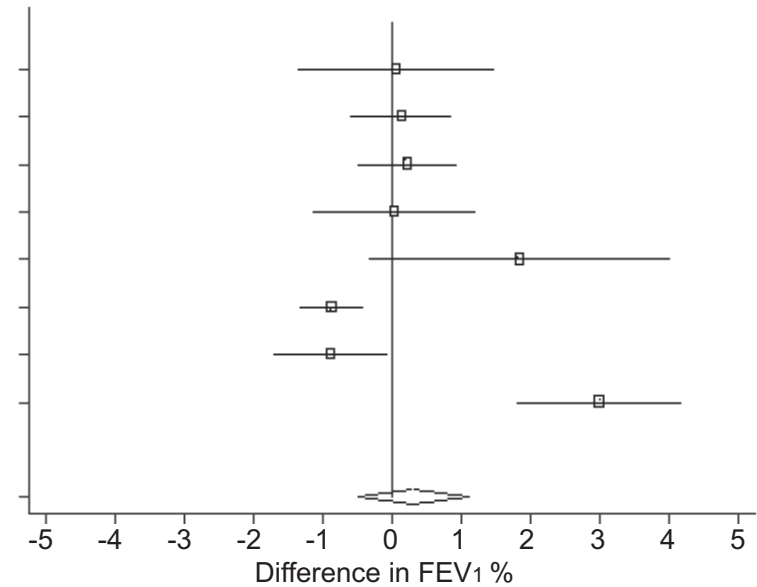

d)

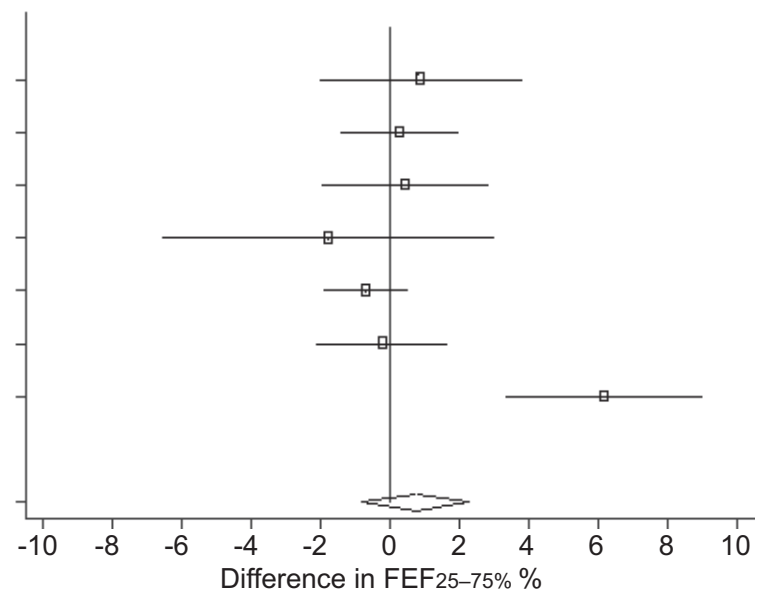

FIGURE 3. Forest plots of study-specific and mean effects of particulate matter with a $50 \%$ cut-off aerodynamic diameter of $10 \mu \mathrm{m}$ (PM10) for a) forced vital capacity (FVC), b) forced expiratory volume in $1 \mathrm{~s}$ (FEV1), c) peak expiratory flow (PEF) and d) forced expiratory flow at 25-75\% of the FVC (FEF25-75\%). Figures are given as percentage difference in lung function per $10-\mu \mathrm{g} \cdot \mathrm{m}^{-3}$ increase in PM10 from single pollutant models, adjusted for individual risk factors. The vertical line indicates null, i.e. $0 \%$ change (no effect), and horizontal lines represent 95\% confidence intervals of estimates. "Combined" indicates the mean and its confidence interval of the individual estimates.

TABLE 5 Combined estimates for the fully adjusted effect of a $10-\mu \mathrm{g} \cdot \mathrm{m}^{-3}$ increase in particulate matter with a $50 \%$ cut-off aerodynamic diameter of $10 \mu \mathrm{m}$ on lung function in different subgroups

FVC

FEV1
FEF25-75\%

$1.0(-0.8-2.7)$
$0.2(-1.2-1.7)$

$$
0.1(-0.6-0.8)
$$

$0.1(-1.2-1.4)$

$0.4(-0.6-1.4)$

$0.4(-0.6-1.4)$

$-0.4(-1.3-0.5)$

$0.6(-0.8-2.0)$

$0.0(-0.9-0.9$
$0.1(-2.4-2.6)$

$1.2(-0.6-3.0)$

$1.0(-0.8-2.8)$

$-0.3(-3.9-3.3)$

$1.2(-0.7-1.1)$

$0.6(-1.8-3.0)$
PEF

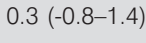

$-0.4(-1.1-0.3)$

Data are presented as \% difference (95\% confidence interval). FVC: forced vital capacity; FEV1: forced expiratory volume in 1 s; FEF25-75\%: forced expiratory flow at 25-75\% of the FVC; PEF: peak expiratory flow. Combined effect estimates calculated from country-specific estimates using random effects model 
personal exposure of subjects is strongly related to the outdoor air pollution level measured at a central site in the community [25]. For individual subjects, differences in exposure from the population average may occur. However, much of the measurement error is likely to be Berkson error, which generally does not lead to bias [26]. Finally, the Swiss SAPALDIA (Swiss study on Air Pollution and Lung Disease In Adults) and the Children's Health study study reported an effect of both within and between community contrasts in $\mathrm{NO}_{2}$ exposure on lung function of adults and children's respiratory symptoms [7, 27, 28]. Chronic bronchitis of adults in the European Community Respiratory Health Survey was associated with individual level variables representing traffic, but not centre level variables such as the central site PM2.5 concentration [29]. In that study, the between-community contrast, however, was largely due to differences between countries, a contrast that we specifically decided not to assess because of the potential for too many differences for which we did not have data. Despite the value of assessing community-level pollution, there is a clear need for assessment of the health effects of near-traffic exposures. There is, for example, some evidence that asthma incidence in children and adults may be associated with near-traffic exposures and not with urban background pollution [30].

In conclusion, our study adds to the evidence that long-term exposure to outdoor air pollution, characterised by the concentration of PM10, is associated with increased respiratory symptoms (phlegm and morning cough) in children. We did not find an association between PM10 and lung function, possibly due to modest pollution levels and heterogeneity across studies.

\section{SUPPORT STATEMENT}

The PATY study was funded by the EU Fifth Framework Quality of Life Programme (contract number QLRT-2001-02544).

\section{STATEMENT OF INTEREST}

None declared.

\section{ACKNOWLEDGEMENTS}

The study was coordinated by T. Fletcher (London School of Hygiene and Tropical Medicine, London, UK).

Author affiliations are as follows. G. Hoek: Institute for Risk Assessment Sciences (IRAS), Utrecht University, Utrecht, the Netherlands; S. Pattenden: London School of Hygiene and Tropical Medicine, London, UK; S. Willers: Institute for Risk Assessment Sciences (IRAS), Utrecht University, Utrecht, the Netherlands; T. Antova: Environmental Health Unit, NCPHP, Sofia, Bulgaria; E. Fabianova: Regional Authority of Public Health, Banska Bystrica, Slovakia; C. Braun-Fahrländer: Swiss Tropical and Public Health Institute and University of Basel, Basel, Switzerland; F. Forastiere: Dept of Epidemiology, ASL Rome, Rome, Italy; U. Gehring: Institute for Risk Assessment Sciences (IRAS), Utrecht University, Utrecht, the Netherlands and Helmholtz Zentrum München, Institute of Epidemiology, Neuherberg, Germany; H. Luttmann-Gibson: Dept of Environmental Health, Harvard School of Public Health, Boston, MA, USA; L. Grize: Swiss Tropical and Public Health Institute and University of Basel, Basel, Switzerland; J. Heinrich: Helmholtz Zentrum München, Institute of Epidemiology, Neuherberg, Germany; D. Houthuijs: National Institute Public Health and the Environment (RIVM), Bilthoven, the Netherlands; N. Janssen: Institute for Risk Assessment Sciences (IRAS), Utrecht University, Utrecht and the National Institute Public Health and the Environment (RIVM), Bilthoven, the Netherlands; B. Katsnelson: Ural Regional Centre for Environmental Epidemiology, Ekaterinburg, Russia; A. Kosheleva: Ural Regional Centre for Environmental Epidemiology, Ekaterinburg, Russia; H. Moshammer: Institute of Environmental
Health, Medical University of Vienna, Vienna, Austria; M. Neuberger: Institute of Environmental Health, Medical University of Vienna, Vienna, Austria; L. Privalova: Ural Regional Centre for Environmental Epidemiology, Ekaterinburg, Russia; P. Rudnai: National Institute of Environmental Health, "Fodor Jozsef" National Center for Public Health, Budapest, Hungary; F. Speizer: Dept of Environmental Health, Harvard School of Public Health, Boston, MA, USA; H. Slachtova: Institute of Public Health, Center of Health Services, Ostrava, Czech Republic; H. Tomaskova: Institute of Public Health, Center of Health Services, Ostrava, Czech Republic; R. Zlotkowska: Epidemiology Dept, Institute of Occupational Medicine and Environmental Health, Sosnowiec, Poland; and T. Fletcher: London School of Hygiene and Tropical Medicine, London, UK.

\section{REFERENCES}

1 Weinmayr G, Romeo E, De Sario M, et al. Short-term effects of $\mathrm{PM} 10$ and $\mathrm{NO}_{2}$ on respiratory health among children with asthma or asthma-like symptoms: a systematic review and meta-analysis. Environ Health Perspect 2010; 118: 449-457.

2 World Health Organization. Systematic review of air pollution, a global update. Geneva, World Health Organization, 2006.

3 Dockery DW, Speizer FE, Stram DO, et al. Effects of inhalable particles on respiratory health of children. Am Rev Respir Dis 1989; 139: 587-594.

4 Dockery DW, Cunningham J, Damokosh AI, et al. Health effects of acid aerosols on North American children: respiratory symptoms. Environ Health Perspect 1996; 104: 500-505.

5 Heinrich J, Hoelscher B, Wjst M, et al. Respiratory diseases and allergies in two polluted areas in East Germany. Environ Health Perspect 1999; 107: 53-62.

6 Kramer U, Behrendt H, Dolgner R, et al. Airway diseases and allergies in East and West German children during the first 5 years after reunification: time trends and the impact of sulphur dioxide and total suspended particles. Int J Epidemiol 1999; 28: 865-873.

7 Peters JM, Avol E, Gauderman WJ, et al. A study of twelve Southern California communities with differing levels and types of air pollution. II. Effects on pulmonary function. Am J Respir Crit Care Med 1999; 159: 768-775.

8 Peters JM, Avol E, Navidi W, et al. A study of twelve Southern California communities with differing levels and types of air pollution. I. Prevalence of respiratory morbidity. Am J Respir Crit Care Med 1999; 159: 760-767.

9 Hirsch T, Weiland SK, von Mutius E, et al. Inner city air pollution and respiratory health and atopy in children. Eur Respir J 1999; 14: 669-677.

10 Janssen NA, Brunekreef B, van Vliet P, et al. The relationship between air pollution from heavy traffic and allergic sensitization, bronchial hyperresponsiveness, and respiratory symptoms in Dutch schoolchildren. Environ Health Perspect 2003; 111: 1512-1518.

11 Braun-Fahrlander C, Vuille JC, Sennhauser FH, et al. Respiratory health and long-term exposure to air pollutants in Swiss schoolchildren. SCARPOL Team. Swiss Study on Childhood Allergy and Respiratory Symptoms with Respect to Air Pollution, Climate and Pollen. Am J Respir Crit Care Med 1997; 155: 1042-1049.

12 Oftedal B, Brunekreef B, Nystad W, et al. Residential outdoor air pollution and lung function in schoolchildren. Epidemiology 2008; 19: 129-137.

13 Raizenne M, Neas LM, Damokosh AI, et al. Health effects of acid aerosols on North American children: pulmonary function. Environ Health Perspect 1996; 104: 506-514.

14 Gotschi T, Heinrich J, Sunyer J, et al. Long-term effects of ambient air pollution on lung function: a review. Epidemiology 2008; 19: 690-701.

15 Gauderman WJ, Avol E, Gilliland F, et al. The effect of air pollution on lung development from 10 to 18 years of age. N Engl J Med 2004; 351: 1057-1067. 
16 Pattenden S, Hoek G, Braun-Fahrlander $\mathrm{C}$, et al. $\mathrm{NO}_{2}$ and children's respiratory symptoms in the PATY study. Occup Environ Med 2006; 63: 828-835.

17 Moshammer H, Hoek G, Luttmann-Gibson H, et al. Parental smoking and lung function in children: an international study. Am J Respir Crit Care Med 2006; 173: 1255-1263.

18 Pattenden S, Armstrong BG, Houthuijs D, et al. Methodological approaches to the analysis of hierarchical studies of air pollution and respiratory health - examples from the CESAR study. Central European Study on Air pollution and Respiratory Health. J Expo Anal Environ Epidemiol 2000; 10: 420-426.

19 Agabiti N, Mallone S, Forastiere F, et al. The impact of parental smoking on asthma and wheezing. SIDRIA Collaborative Group. Studi Italiani sui Disturbi Respiratori nell'Infanzia e l'Ambiente. Epidemiology 1999; 10: 692-698.

20 Katsnelson B, Kuzmin SV, Privalova L, et al. [Chronic respiratory disease risk factors in younger schoolchildren dwelling in towns with different levels of ambient air pollution]. Vestnnik Uralskoy Medizinskoy Akademicheskoy Nauki 2007; 16: 27-37.

21 Gehring U, Pattenden S, Slachtova H, et al. Parental education and children's respiratory and allergic symptoms in the Pollution and the Young (PATY) study. Eur Respir J 2006; 27: 95-107.

22 DerSimonian R, Laird N. Meta-analysis in clinical trials. Control Clin Trials 1986; 7: 177-188.
23 Stanojevic S, Wade A, Cole TJ, et al. Spirometry centile charts for young Caucasian children: the Asthma UK Collaborative Initiative. Am J Respir Crit Care Med 2009; 180: 547-552.

24 Nicolai T, Carr D, Weiland SK, et al. Urban traffic and pollutant exposure related to respiratory outcomes and atopy in a large sample of children. Eur Respir J 2003; 21: 956-963.

25 Monn C, Brandli O, Schindler C, et al. Personal exposure to nitrogen dioxide in Switzerland. SAPALDIA team. Swiss Study on Air Pollution and Lung Diseases in Adults. Sci Total Environ 1998; 215: 243-251.

26 Armstrong BG. Effect of measurement error on epidemiological studies of environmental and occupational exposures. Occup Environ Med 1998; 55: 651-656.

27 Schindler C, Ackermann-Liebrich $\mathrm{U}$, Leuenberger $\mathrm{P}$, et al. Associations between lung function and estimated average exposure to $\mathrm{NO}_{2}$ in eight areas of Switzerland. The SAPALDIA Team. Swiss Study of Air Pollution and Lung Diseases in Adults. Epidemiology 1998; 9: 405-411.

28 Gauderman WJ, Avol E, Lurmann F, et al. Childhood asthma and exposure to traffic and nitrogen dioxide. Epidemiology 2005; 16: 737-743.

29 Sunyer J, Jarvis D, Gotschi T, et al. Chronic bronchitis and urban air pollution in an international study. Occup Environ Med 2006; 63: 836-843.

30 Perez L, Rapp R, Künzli N. The Year of the Lung: outdoor air pollution and lung health. Swiss Med Wkly 2010; 140: w13129. 